\title{
Ozonolysis of phospholipid double bonds during electrospray ionization: a new tool for structure determination
}

\author{
Michael C. Thomas ${ }^{\dagger}$, Todd W. Mitchell ${ }^{\ddagger}$, Stephen J. Blanksby ${ }^{\dagger}$ \\ Departments of Chemistry ${ }^{\dagger}$ and Biomedical Science ${ }^{\ddagger}$ University of Wollongong, Wollongong NSW, \\ 2522, Australia.
}

Address reprint requests to Dr Stephen J. Blanksby, Department of Chemistry, University of Wollongong, Wollongong NSW, 2522, Australia. E-mail blanksby@uow.edu.au 
Supporting Information Figure 1. A photograph taken of the corona discharge observed at the electrospray ionization needle of the ThermoFinnigan LTQ ion trap mass spectrometer when oxygen is used at the electrospray nebulizing gas and an electrospray voltage of $-6 \mathrm{kV}$ is applied. An expanded view of the discharge is also shown.
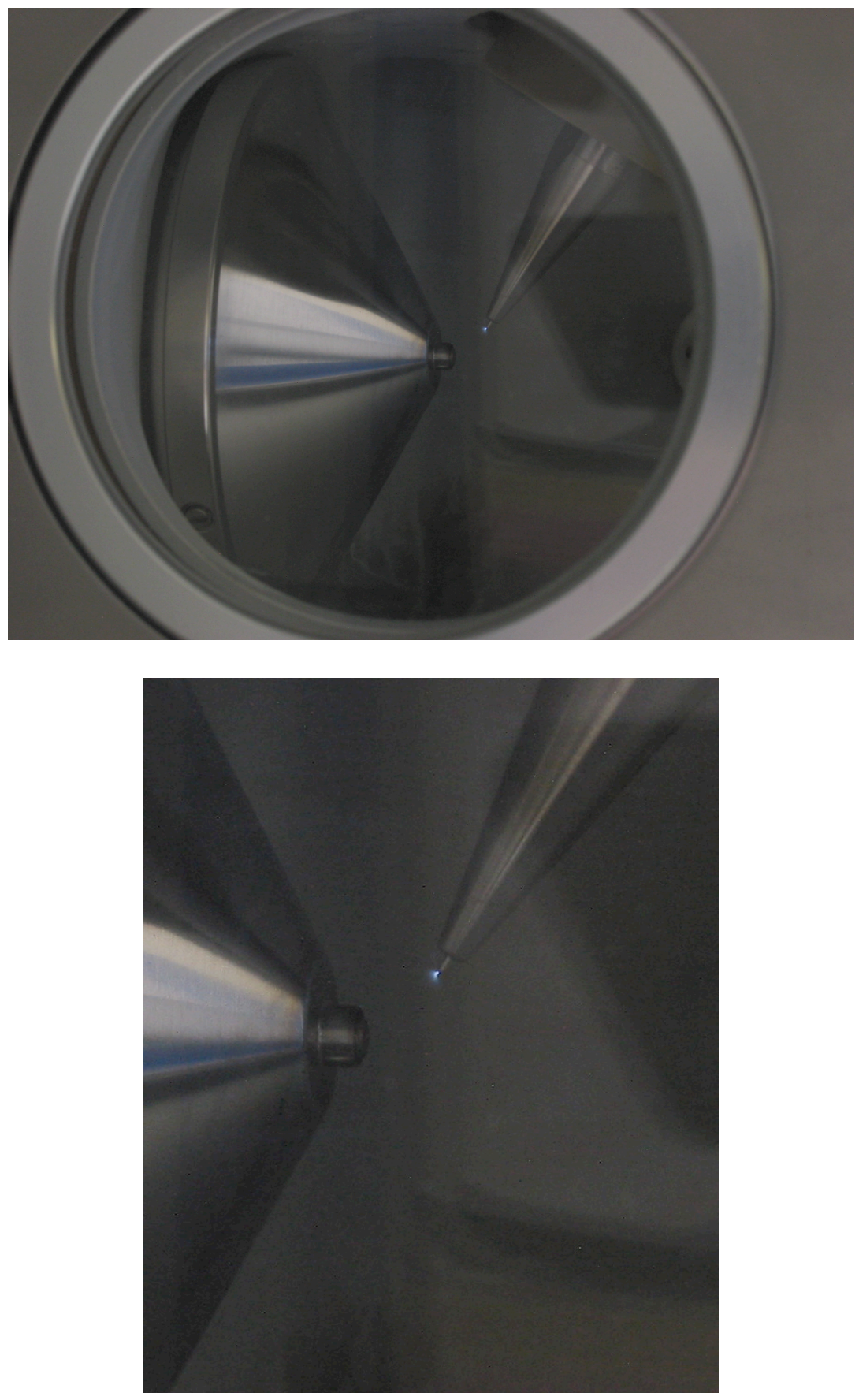
Supporting Information Figure 2. ESI-MS spectra of GPA(16:0/9Z-18:1) measured on the ThermoFinnigan LTQ ion trap mass spectrometer with (a) $\mathrm{D}_{4}$-methanol, $\mathrm{O}_{2},-5 \mathrm{kV}$ and (b) ethanol, $\mathrm{O}_{2}$, $-5 \mathrm{kV}$. Both chemically induced fragment ions in (a) are mass-shifted by an additional 1 Da due to deuterium exchange of the phosphate proton.

(a)
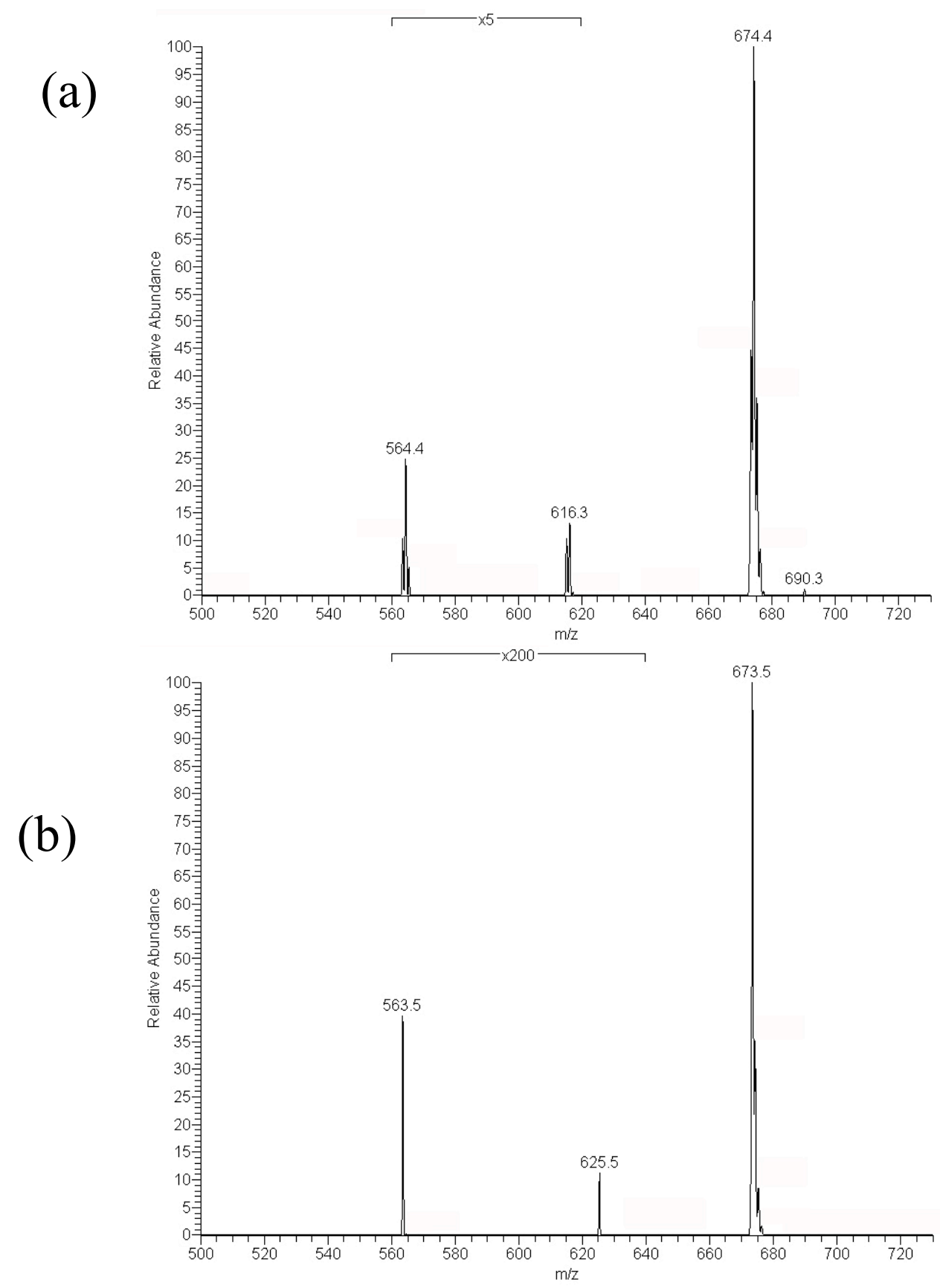
Supporting Information Figure 3. ESI-MS/MS spectra of source formed (a) $\mathrm{m} / \mathrm{z} 563$ and (b) $\mathrm{m} / z 611$ ions from ozonolysis of $\left[\mathrm{GPA}(16: 0 / 9 \mathrm{Z}-18: 1)-\mathrm{H}^{-}\right.$measured using the ThermoFinnigan LTQ ion trap mass spectrometer.

(a)
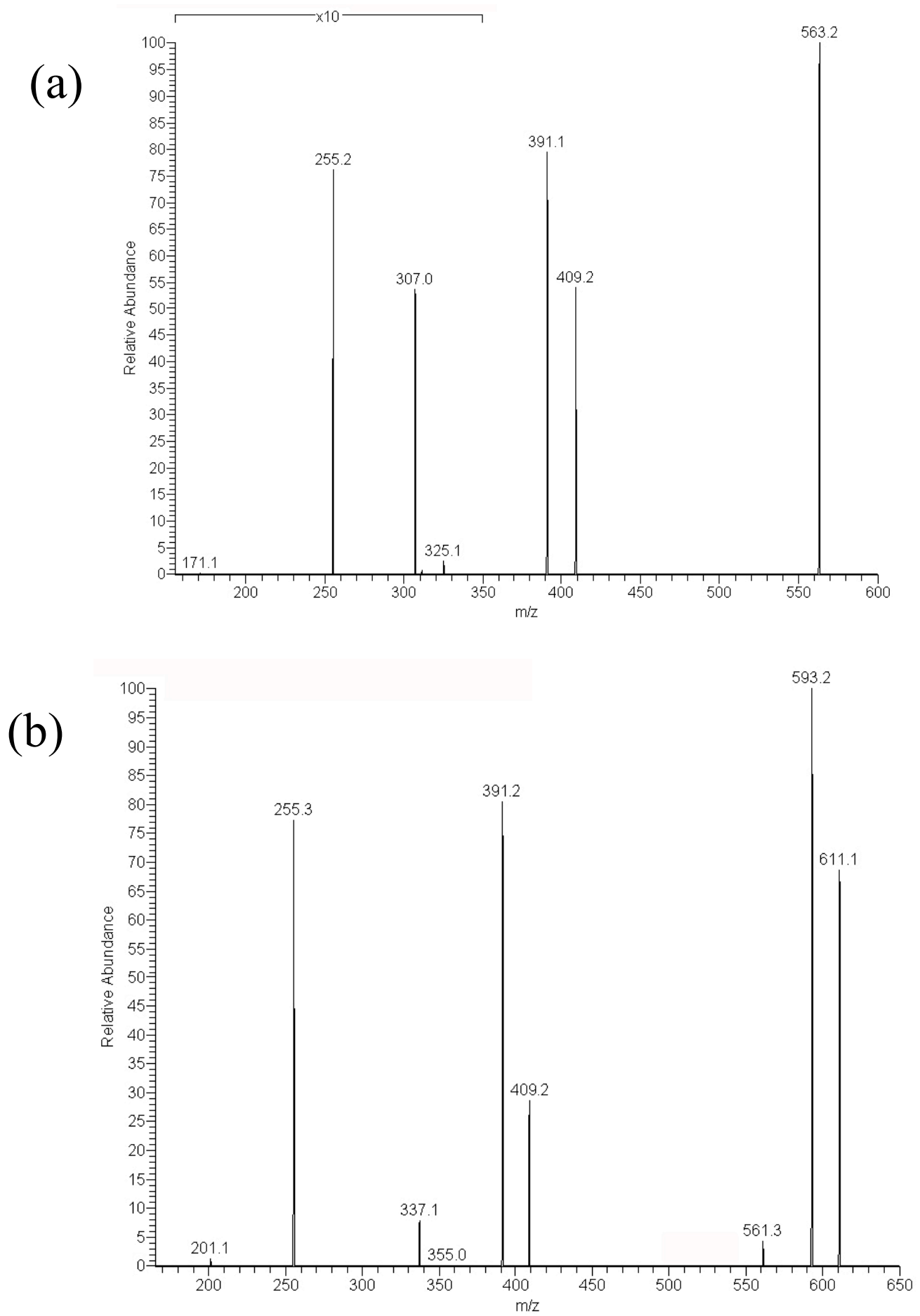
Supporting Information Figure 4. In-source discharge ozonolysis ESI-MS spectrum of doubly charged tetraoleoylcardiolipin $\left[\mathrm{CL}(9 \mathrm{Z}-18: 1)_{4}-2 \mathrm{H}\right]^{2-}$ measured using the ThermoFinnigan LTQ ion trap mass spectrometer. The chemically induced fragments observed correspond to doubly charged aldehydes and $\alpha$-methoxyhydroperoxides and combinations resulting from multiple ozonolysis events on the same cardiolipin molecule. The fragment at $\mathrm{m} / \mathrm{z} 687.5$ results from water loss from the doubly charged $\alpha$-methoxyhydroperoxide at $m / z 696.5$.

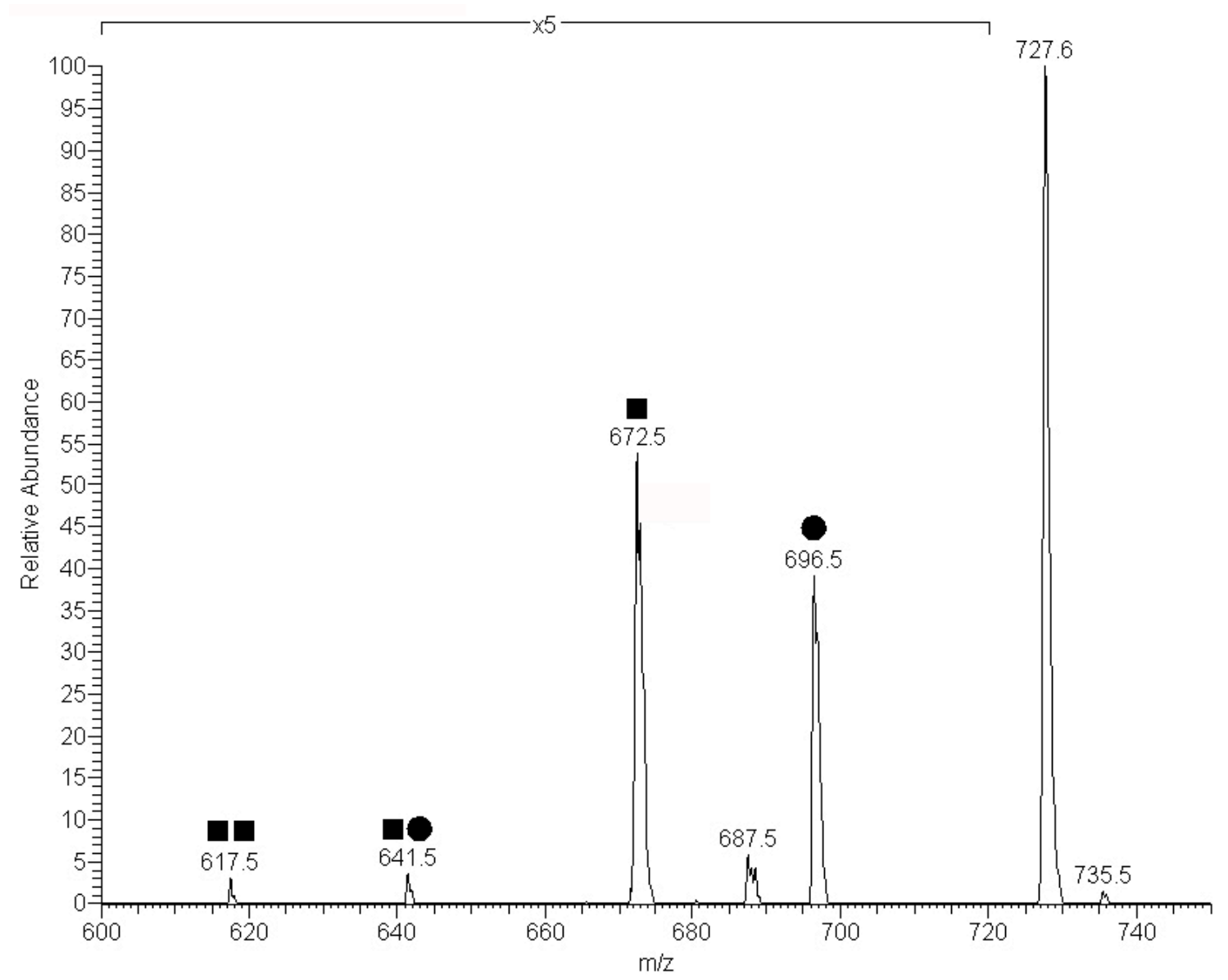


Supporting Information Figure 5. In-source ozonolysis ESI-MS spectrum of 1,2-dioleoyl-sn-glycero3-phosphocholine, [GCho(9Z-18:1,9Z-18:1)+H] ${ }^{+}$, obtained in positive ion mode using an ozone generator on the Micromass QuattroMicro triple quadrupole mass spectrometer. The chemically induced fragments observed correspond to charged $\mathbf{\square}$ aldehydes and $\boldsymbol{\alpha}$-methoxyhydroperoxides, with both protonated $\left(\mathrm{H}^{+}\right)$and sodiated $\left(\mathrm{Na}^{+}\right)$cations observed.

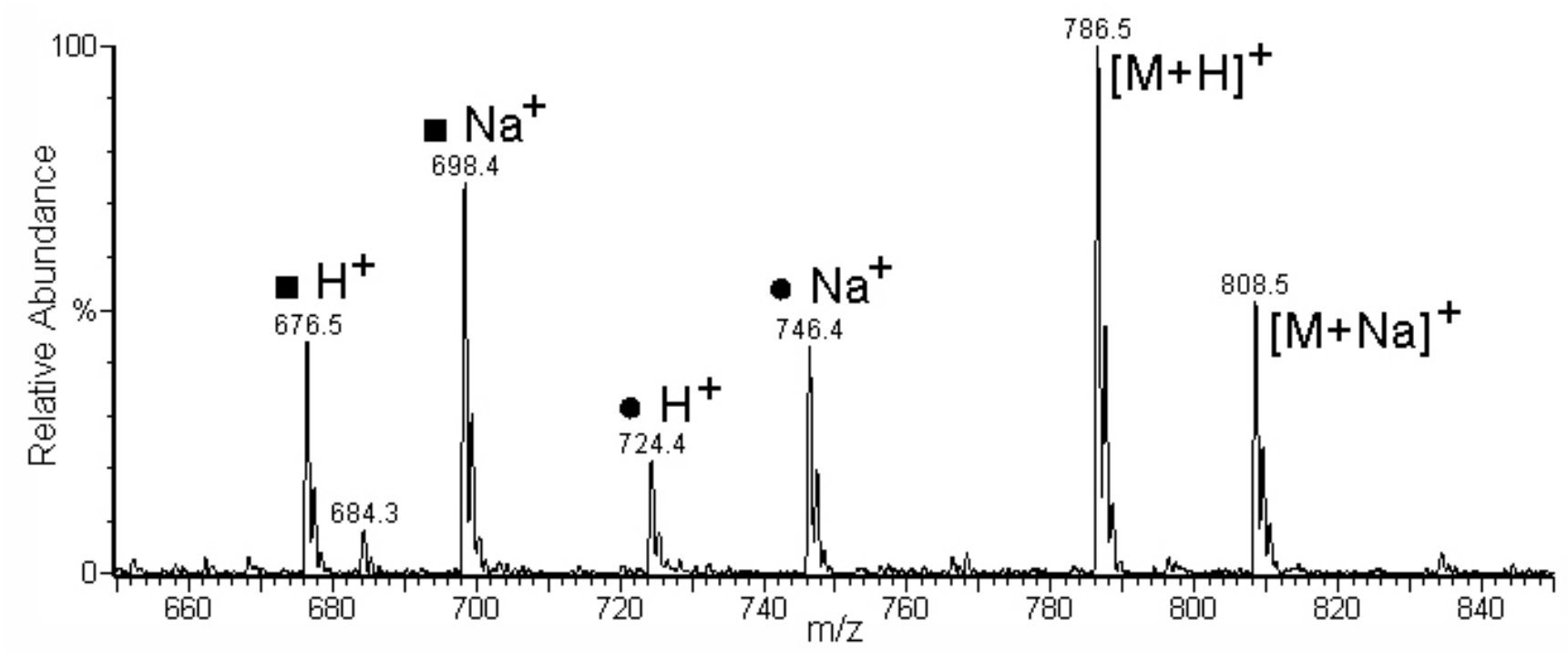




\section{Detailed Methods}

\section{Materials and Sample Preparation}

All phospholipids were purchased from Avanti Polar Lipids, Inc. (Alabaster, AL) and were used without further purification. HPLC grade methanol and AR grade ethanol were purchased from Crown Scientific (Sydney, Australia). D4-methanol (99.8 atm\%, Cambridge Isotopes, MA) was purchased from Sigma-Aldrich (Castle Hill, Australia). Phospholipid solutions were prepared at concentrations of $10 \mu \mathrm{M}$ in the appropriate solvent. Industrial grade compressed oxygen (purity 99.5\%) was obtained from BOC gases (Cringila, Australia).

\section{Instrumentation}

Most experiments were performed on a ThermoFinnigan LTQ (Waltham, MA) fitted with a conventional IonMax electrospray ionization source. Spectra were obtained by infusion of a standard solution ( $8 \mu \mathrm{L} / \mathrm{min}$ ), typical settings were; spray voltages between -4-6 kV, capillary temperature 275 ${ }^{\circ} \mathrm{C}$, sheath and auxiliary gas flow rates set at 10 and 5 (arbitrary units), respectively. Oxygen was delivered to the instrument by connecting a cylinder of compressed oxygen to the press fitting on the back of the instrument designated for the nitrogen gas supply. With oxygen as the nebulizing gas Corona discharge was typically observed with spray voltages in the range of $-5-6 \mathrm{kV}$.

WARNING: Although no problems were encountered by the authors, it should be noted that initiating a corona discharge in a gaseous atmosphere of methanol and oxygen presents a potential explosion hazard. Care should be taken at high solvent flow rates, where the gas volume ratio of methanol:oxygen can become significant. 
Experiments requiring an ozone generator were performed on a Micromass QuattroMicro (Manchester, UK). The $\mathrm{O}_{3} / \mathrm{O}_{2}$ gas mixture was introduced into the ESI source by attaching the outlet of the ozone generator directly to the desolvation gas press fitting on the front of the instrument. The ozone was generated from a modified $\mathrm{NO}_{\mathrm{x}}$ analyzer (Model 8840, Monitor Labs, $\mathrm{CO}$ ). The spectrum shown in Figure 1(e) was acquired in negative ion mode by infusion of a $5 \mu \mathrm{M}$ methanolic solution at $10 \mu \mathrm{L} / \mathrm{min}$ with a desolvation gas flow rate of $160 \mathrm{~mL} / \mathrm{min}$. The capillary and cone voltages were $-3 \mathrm{kV}$ and $25 \mathrm{~V}$ respectively. The spectrum shown in supporting information Figure 5 was obtained in positive ion mode by infusion of a $5 \mu \mathrm{M}$ methanolic solution at $10 \mu \mathrm{L} / \mathrm{min}$ with a desolvation gas flow rate of 160 $\mathrm{mL} / \mathrm{min}$. The capillary and cone voltages were $+3.5 \mathrm{kV}$ and $30 \mathrm{~V}$ respectively. In all experiments the source temperature was maintained at $80^{\circ} \mathrm{C}$ and the desolvation gas at $120^{\circ} \mathrm{C}$. 